Review Article

\title{
Emergence of a Zoonotic Pathogen - Novel Coronavirus (SARS-CoV-2) in the Context of Changing Environment
}

\author{
Sajal Bhattacharya', Shakya Sinha ${ }^{2}$, Debasmita Baidya ${ }^{3}$, Rina Tilak $^{4}$
}

${ }^{1}$ Associate Professor, Post Graduate Department of Zoology, Asutosh College (University of Calcutta), Kolkata, West Bengal, India. ${ }^{2}$ Post Graduate Student, Post Graduate Department of Zoology, Dinabandhu Andrews College (University of Calcutta), Kolkata, West Bengal, India.

${ }^{3}$ Research Scholar, Post Graduate Department of Zoology, Asutosh College (University of Calcutta), Kolkata, West Bengal, India. ${ }^{4}$ Scientist 'G', Dept. of Community Medicine, Armed Forces Medical College, Pune, Maharashtra, India.

DOI: https://doi.org/10.24321/0019.5138.202021

I $\quad \begin{array}{lllll}\mathbf{N} & \mathbf{F} & \mathbf{O}\end{array}$

Corresponding Author:

Rina Tilak, Dept. of Community Medicine, Armed Forces Medical College, Pune, Maharashtra, India.

E-mail Id:

rinatilak@hotmail.com

Orcid Id:

https://orcid.org/0000-0003-3781-0210

How to cite this article:

Bhattacharya S, Sinha S, Baidya D, Tilak R. Emergence of a Zoonotic Pathogen - Novel Coronavirus (SARS-CoV-2) in the Context of Changing Environment. J Commun Dis 2020; 52(2): 18-24.

Date of Submission: 2020-05-16

Date of Acceptance: 2020-06-10
$\begin{array}{lllllllll}\mathbf{A} & \mathbf{B} & \mathbf{S} & \mathbf{T} & \mathbf{R} & \mathbf{A} & \mathbf{C} & \mathbf{T}\end{array}$

A newly discovered strain of coronavirus is the causal agent of COVID-19 pandemic. Preliminary findings suggest that this novel coronavirus Severe Acute Respiratory Syndrome Coronavirus 2 (SARS-CoV-2) might have originated in bats, and thereafter crossed the species barrier from an intermediate host; eventually spreading within humans. Bat coronaviruses are older than the coronaviruses identified in other animals and have shown a consistent growth rate. The diverse natures of coronaviruses in different bat species have witnessed repeated introductions and occasional establishment in other animal species. The dispersion of animal diseases and zoonotic pathogens is facilitated by rapid globalization, international trading and the ever-growing flow of goods and people. Climate change coupled with globalization and extensive deforestation can act as a significant selection pressure which can lead to onsets of future coronavirus transmission cycles. Climate change alters the availability of viable habitat for the hosts as well which results in the redistribution of host ranges and host densities relative to habitat resources. An attempt has been made in this review to assess and analyze the possible causes of the emergence of a zoonotic pathogen having pandemic potential, the novel coronavirus (SARS-CoV-2) and its subsequent spill over to humans causing COVID-19.

Keywords: SARS-CoV-2, Reservoir Host, Man-animal Encounter, Climate Change, Deforestation, Travel and Trade

\section{Introduction}

Most of the human infectious diseases, especially caused by the viral pathogens that are surfacing recently, originate from animals and presents a significant global health burden. ${ }^{1}$ Twenty-seven cases of pneumonia were identified in Wuhan City, within the Hubei province in China, with unknown etiology, on 31st December 2019. ${ }^{2}$ The identified pathogen was subsequently named Severe Acute Respiratory Syndrome Coronavirus 2 (SARS-CoV-2) and the disease is named as COVID-19. ${ }^{3}$ Coronaviruses (CoVs) belong to the family Coronaviridae, subfamily Orthocoronavirinae and the 
order Nidovirales. The CoVs get their nomenclature from their structure having an enveloped, crown-like viral particle. ${ }^{4}$ Bat coronaviruses are older than those coronaviruses identified in other animals as per the data from lineage studies, and it is also evident that the human Severe Acute Respiratory Syndrome (SARS) coronavirus was derived directly from the coronaviruses found in wild animals of wet markets in southern China. ${ }^{5}$ Notably, novel Coronavirus (SARS-CoV-2) was closely related, with an $88 \%$ identical genome, to two bat-derived SARS-like coronaviruses - bat-SL-CoVZC45 and bat-SL-CoVZXC21. ${ }^{6}$ In between 1940 to 2004, a time span of 64 years implicated a total number of 335 zoonotic diseases which signifies the role of wildlife as the source of emerging pathogens. ${ }^{7}$ Climate change is believed to have effects on the evolution of pathogens, and their vectors, wherever relevant, and can act as selection pressure leading to changes in viral transmissibility. Tourism, eco-tourism has exponentially increased in the recent years creating frequent encounter opportunities between wild animals and humans. ${ }^{7}$ These findings can suggest the possible routes to an increasing number of imported zoonoses. An attempt has been made in this review to assess and analyze the possible causes of the emergence of a zoonotic pathogen having pandemic potential, the novel coronavirus (SARS- CoV-2) and its subsequent spill over to humans causing COVID-19.

\section{Methodology}

PubMed, Google Scholar, and several other journals were searched for studies concerning the Viral Zoonotic Diseases, with special reference to SARS-CoV-2. All the findings and observations in this review regarding the focused topic are based on published information as listed in the references. Data of case incidences and deaths were collected from www.who.int (Accessed on $25^{\text {th }}$ April, 2020). ${ }^{8}$

\section{The Emergences of Human Coronavirus}

Since 2003, several new human coronaviruses have been identified, one amongst which includes the severe acute respiratory syndrome coronavirus (SARS-CoV). This SARS-CoV has significantly caused morbidity and mortality. ${ }^{9}$ The virus was isolated from southern China in between 2002-2003 and spread rapidly to different parts of the world. ${ }^{10-12}$ Genome sequencing from the virus drawn from SARS patients, wild and farmed civets, and other animals, generated a dendrogram showing a close resemblance between the first human SARS coronaviruses to that of a contemporary virus from masked palm civets. ${ }^{13}$ However, two independent Chinese groups reported the first bat SARS-related CoV (SARS-CoV) in 2005 showed an immediate relatedness of the human SARS-CoV to the bat SARS like-CoV, implicating a bat origin of the former. ${ }^{14,15}$ In addition, divergence dates for SARS-CoV and SARS-like Bt-CoVs indicated that the precursors of SARS-CoV might have circulated in an unidentified host before the 2003 epidemic. ${ }^{5}$ SARS-CoV infected around 8000 individuals as it gradually spread to other parts of the world with an overall mortality of $10 \%$ during the $2002-2003$ epidemics. ${ }^{10}$ The Middle East respiratory syndrome coronavirus (MERS-CoV) another highly pathogenic $\beta$-CoV has caused epidemics in humans since $2012 .{ }^{16}$ Since then, more bat coronaviruses were identified and isolated in China. ${ }^{4}$ Recently identified coronavirus was named SARS-CoV- 2 by WHO. Research revealed the highly identical genome sequence of the SARS-CoV-2 to that of the bat coronavirus, indicating bat as the likely natural host. The SARS-CoV-2 uses angiotensinconverting enzyme 2 (ACE2), the same receptor that is also used by the SARS-CoV; primarily distributed in the respiratory tract. ${ }^{17}$

\section{Zoonotic Sources of Coronaviruses}

The animal origin of SARS-CoV was initially identified to be civet cats, but soon bats were found to be most likely natural reservoir hosts of this virus. ${ }^{18}$ Epidemiological studies showed that the earliest cases of SARS were associated with the wildlife meat industry. A market survey of wildlife in the Shenzhen city of China, recovered SARS-CoV-like viruses from masked palm civets (Paguma larvata) and raccoon dogs (Nyctereutes procyonoides). Additionally, the survey led to the detection of antibodies against the SARS-CoV-like virus in hog badgers (Arctonyx collaris). ${ }^{18}$ The Middle East dromedary camels were generally accepted as the major source in animals, for the zoonotic transmission of human Middle East Respiratory Syndrome (MERS). However, bats were then found to harbor CoVs that shared common ancestry with that of the MERS-CoV. ${ }^{19}$ Preliminary findings suggest that this novel coronavirus (SARS-CoV-2) originated in bats and thereafter crossed the species barrier from an intermediate host; eventually spreading within humans. ${ }^{20}$ Nevertheless, according to recent research pangolins, snakes, and minks are the suspected reservoirs and hosts of SARS-CoV-2. ${ }^{21-23}$ Further studies indicated ferrets and cats (Table 1) to be highly susceptible to SARS-CoV-2. ${ }^{24}$ Apart from SARS-CoV, SARS-CoV-2 and MERS-CoV, some other alpha coronavirus and beta coronavirus are found in several animal hosts and intermediate hosts such as rodents, bovine, camelids, masked palm civets etc. (Table 1 ). ${ }^{25}$

\section{Bat as a Possible Ideal Reservoir Host of Coronaviruses}

Bats have been identified as a natural reservoir for a number of emerging zoonotic viruses. ${ }^{26}$ Bats have been found to harbor a number of coronaviruses including those causing SARS, MERS, porcine epidemic diarrhea (PED) and Severe Acute Diarrhea Syndrome (SADS). ${ }^{27}$ However, SARS-likeCoVs in different species of horseshoe bats of the genus Rhinolophus are vital for the understanding of the bat coronavirus. ${ }^{26}$ Bats have a vast range of distribution on all continents except Antarctica. The ability of these mammals to fly long distances during seasonal migrations, make 
them unique to their class. ${ }^{28}$ The exchange of novel viruses or virus variants may be possible between migrating and non-migrating conspecific subpopulations of bats ${ }^{29}$ due to exclusive migration patterns. Bat populations may be panmictic or may exist as metapopulations which offer a potential for seasonal transmission of the virus and annual outbreaks of viral diseases. Periodic outbreaks may also spark up among spatially discrete populations. ${ }^{29}$ Bats were among the earliest mammalian species to evolve. It is possible that their innate and acquired immune responses have important qualitative or quantitative differences from those of the rodents and primates which allow them to maintain the virus within them for a long time. ${ }^{29}$ The rectal swabs from eight Rousettus sp. and twenty one Pteropus sp. were found positive for CoV RdRp gene according to a data of collected from bat samples across seven states of India. ${ }^{30}$

Table I.Hosts/suspected hosts of human coronaviruses

\begin{tabular}{|c|c|c|}
\hline Coronavirus & Hosts/ Suspected hosts & Reference \\
\hline \multirow{3}{*}{ SARS-CoV } & Palm civets & \multirow{2}{*}{ Bolles et al., 2011} \\
\hline & Raccoon dogs & \\
\hline & Ferret badgers & Guan Y et al., 2003 \\
\hline SARS-like CoV & Horseshoe bats & Lau SK et al., 2005 \\
\hline $\mathrm{BtCoV}$ & Bats & Drexler et al., 2010 \\
\hline MERS-CoV & Camels & Memish et al., 2013 \\
\hline \multirow{2}{*}{ SADS-CoV } & Horseshoe Bats & \multirow{2}{*}{ Yang et al., 2019} \\
\hline & Swine & \\
\hline \multirow{6}{*}{ SARS-CoV-2 } & Bats & Andersen et al., 2020, Chatterjee R and Bhattacharya S, 2020 \\
\hline & Pangolins & Zheng J, 2020. \\
\hline & Snake & Ji W et al., 2020 \\
\hline & Minks & Cheng ZJ, Shan J, 2020 \\
\hline & Cats & \multirow{2}{*}{ Shi J et al., 2020.} \\
\hline & Dogs & \\
\hline \multirow{3}{*}{$\begin{array}{l}\text { Other Beta } \\
\text { coronaviruses }\end{array}$} & Rodents & \multirow{3}{*}{ Monchatre-Leroy E et al., 2007} \\
\hline & Rabbits & \\
\hline & Hedgehogs & \\
\hline
\end{tabular}

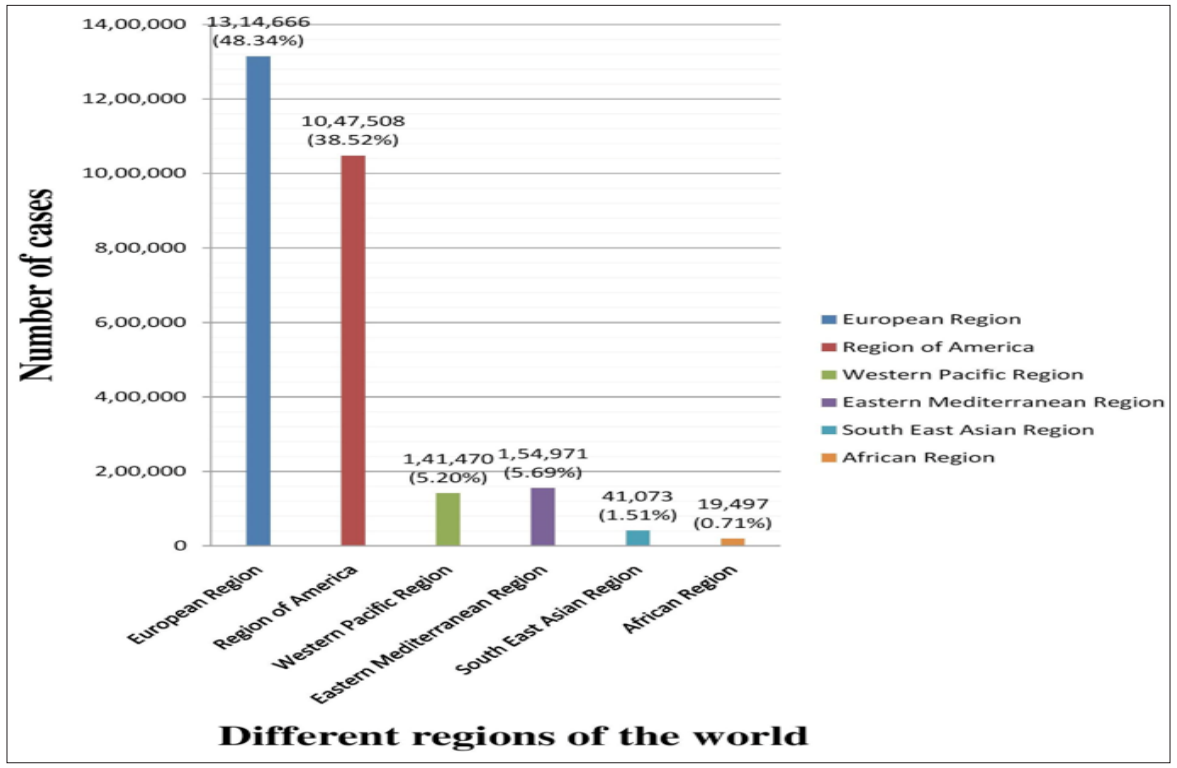

Figure I.Total number of confirmed cases of COVIDI 9 in different WHO categorized region of the world (From 30 ${ }^{\text {th }}$ January 2020 to $25^{\text {th }}$ April 2020) 


\section{The Global Scenario of COVID-19}

The total numbers of COVID19 cases in categorized regions (recommended by WHO) of the world, as per www.who.int (Accessed on $25^{\text {th }}$ April 2020) ${ }^{8}$, are presented in this section. The total number of confirmed cases are 27,19,185 (Figure 1) as of $25^{\text {th }}$ April 2020 declared by WHO. In European region the number of incidences is highest with $13,14,666$ cases, followed by the Region of America with 10,47,508 cases. The European region alone is having $48.34 \%$ of the total cases all over the world, while the region of America is having a share of $38.52 \%$. Total number of COVID-19 cases in Western Pacific Region is 1,41,470, which is $5.20 \%$ of the total cases occurring all over the world. From a total number of $1,54,971$ cases, $5.69 \%$ of the cases overall are reported from Eastern Mediterranean Region. As compared to other regions, the South East Asian Region and African Region are having lower numbers of cases. There are 41,073 and 19,497 cases reported from South East Asian Region and African Region respectively which are $1.51 \%$ and $0.71 \%$ of the total cases (Figure 1).

\section{Man-Animal Encounter and Emergence of Zoonoses}

\section{Deforestation}

Human activities such as logging, road construction, mining and agricultural practices are the major cause of deforestation in the present scenario. ${ }^{31}$ On a global scale, deforestation and degradation of natural habitats are seen to alter the transmission dynamics of diseases as the ecological habitats are being disrupted and reservoir abundance is being changed. ${ }^{7}$ There have been several instances where deforestation had a direct impact on human diseases. ${ }^{32}$ Emergence of viral pathogens, such as SARS, Ebola and various other bat-borne viruses has also been correlated with increased deforestation. ${ }^{33}$ For many years a common belief was that deforestation and anthropisation will eventually lead to the disappearance of species. Anthropized environments can in fact provide an acceptable habitat for a large range of bat species, in turn generating a higher diversity of bats and bat-borne viruses next to human dwellings. ${ }^{34}$ Unlike natural environments, the anthropized environmental niches are largely selective, and these are acceptable for a wide range of bat species, which are usually not encountered together. ${ }^{34,35}$ This increases the risk of transmission of viruses through direct contact, infection from infected domesticated animals or contamination by urine or feces. ${ }^{34}$

\section{Travel, Trade and Tourism}

The dispersion of animal diseases and zoonotic pathogens is facilitated by rapid globalization, international trading and the ever-growing flow of goods and people. Travel plays a significant role in the emergence and spread of diseases.
Travelling across continents facilitates mixing of various species through trade; these activities unknowingly transfer microorganisms to novel niches, incurring pathogenic results. ${ }^{36}$ Human migration has therefore provided the route for entry and spread of infectious diseases and zoonoses (for example, plague, yellow fever, monkey pox, SARS etc.). ${ }^{37}$ Population growth and globalization are two unrelenting forces which combine synergistically to expand possibilities for pathogens to shift from comfortable domains into new unexplored niches which also results in lethality. ${ }^{36}$ However, tourism and immigration together also constitute an interface for mixing different genetic and ecological profiles, along with their cultural and social aspects, which are of particular interest with regards to zoonoses. ${ }^{37}$

\section{Climate Change}

Many studies have focused on the uninhibited relationship between climate change and emerging or re-emerging parasitic diseases. ${ }^{38-40}$ Climate change is believed to have effects on the evolution of pathogens, and their vectors, wherever relevant. Frequent mutation and recombination events lead to the rise in variants having altered levels of fitness that allow it to persist and spread giving rise to pathogenic variants of unknown and altered pathogenic potentials. ${ }^{7}$ Recrudescence of viral replication under stress has been documented in case of human viral diseases and is quite likely to occur even within zoonotic host populations. ${ }^{41,42}$

\section{Discussion}

Emergence and epidemics of viral pathogens are promoted by a number of activities that increase the viral traffic. The pathogens of these epidemics, including most of the novel infections, are found to be zoonotic. ${ }^{43}$ Sixty percent of the estimated emerging human pathogens are zoonotic, of which, more than seventy one percent have origins in the wildlife. ${ }^{7}$ New genetic combinations alter the pathogenic potential which helps them to switch hosts. China and South-East Asia have experienced and registered significantly less case incidences in comparison to that of the European and American regions. Considering the emergence of diverse human coronavirus variants in the last couple of decades, differences in COVID-19 case in different geographical regions may be attributed to genomic variations of SARS-CoV-2 along with other immunogenetic factors. The pathogenic competence may also be modified by changes in socioeconomic, ethological, eco-environmental characteristics of the hosts. ${ }^{7}$ Bats are abundant, diverse, and geographically widespread mammals. The innate characteristics of bats viz. population structure, capability to fly, seasonal migration, food preference, daily movement pattern, life span, colony composition (solitary or colonial), roosting behaviour, hibernation and torpor, echolocation capability, susceptibility to viruses, make them one of the 
most suitable hosts to a multitude of viruses and other disease causing agents. ${ }^{29}$ Viruses that evolved from bats may have used cellular receptors and biochemical pathways, for replication that are conserved in mammals. Bat coronavirus population has shown a consistent growth rate while coronaviruses from other hosts reveal an epidemic like increase. It indicates the diverse nature of coronaviruses that are endemic in different bat species, with repeated introductions and occasional establishment in other species. ${ }^{5}$ It is evident that coronaviruses from bats are older than other coronaviruses recognized from animal species and have wide genetic diversity. Some hypothesis even suggests that flight provides the selection pressure for bats to coexist with the viruses, and the potentials for intra- and interspecies transmission greatly intensifies with the persistence of the virus among long-lived bats. ${ }^{29,}$ ${ }^{44}$ The migratory ability in bats however, has particular relevance in the context of disease transmission. ${ }^{44} \mathrm{Co}$ evolution of coronavirus with that of the mammalian host family has been reported in a study conducted in 2016, wherein genetic segregation was evidenced between coronaviruses in two species of rodents - Myodes sp. and Apodemus species which are reservoir hosts of other CoVs. ${ }^{45}$ Thus, it is alarming to note that host switching might be one of the most remarkable evolutionary mechanisms for the dynamism of the Coronaviruses, evident in the current global pandemic as well. In recent studies, lineagespecific selection pressure analysis, points out only SARS coronaviruses in civets and humans to be under significant positive selection, thereby indicating a possibility of inter-virus recombination. ${ }^{20}$ However, the possibility of human SARS-CoV infecting domesticated mammals, in particular, the pig has been evident. ${ }^{46}$ Ferrets and cats were also found to be susceptible for SARS-CoV-2. ${ }^{24}$ This may indicate an opportunity of possible reverse zoonoses or anthropozoonosis of coronaviruses, adding a new dynamics to its spread. Nevertheless, further investigation in this direction is required to consolidate this hypothesis.

Demographic changes, rapid urbanization, global travel and other environmental changes led the tropical world today to face the greatest challenges arising from emerging, reemerging and spread of zoonotic diseases in the context of climate change. ${ }^{47}$ On a global scale, deforestation and degradation of natural habitats are seen to viably accommodate the intensification of agriculture and living areas for humans. As a result, ecological habitats are being disrupted, reservoir abundance is being changed and transmission dynamics are altered. ${ }^{7}$ Viruses transmitted to humans as a result of habitat destruction were seen to have significantly higher host plasticity as they emerged from the mixing of diverse animal species. ${ }^{1}$ Since multiple host species can have different habitat requirements and are capable of being infected by the same pathogen, a redistribution of host ranges may change the geographic overlap of the species', altering the frequency of their interactions. ${ }^{48}$ Climate change coupled with extensive deforestation and rapid globalization can act as significant selection pressures, further alleviating mutation probabilities leading to the onset of future CoV transmission cycle which may involve different animal hosts. The migration and dispersal of flying animals such as bats, birds etc. can also change because of habitat degradation, exposing additionally fresh populations to novel pathogens. ${ }^{32}$ The impact of reservoir density and diversity on geo-spatial transmission of directly transmitted zoonotic diseases through 'dilution' or 'amplification' effect has been well demonstrated by many authors. ${ }^{49-53}$, however, the same needs validation in transmission dynamics of novel coronavirus. This aspect warrants more research to enable better understanding of the impact of these effects on the transmission potential and possible outbreaks of zoonotic pathogens such as SARS-CoV-2 and their likes in diverse ecological situations.

\section{Conclusion}

The city of Wuhan, Hubei Province, China has been marked as the epicenter of the COVID-19 pandemic caused by SARS-CoV-2. In future China and its adjoining areas could be the flash point of an outbreak of a new variant of SARSCoV-2. Evidently, this region can be considered as a possible ecological nursery of the coronavirus and their reservoir hosts. The focal point of the earlier SARS-CoV epidemic also emerged from this region of Asia. A wide range of communicable diseases caused by zoonotic pathogens originating in wildlife and then spill over to humans. Recurrent encroachment of the wildlife area and repeated encounters with the animal reservoir host of the coronavirus coupled with climate change and deforestation might have created a new variant through selection pressure as evident in case of the novel coronavirus (SARS-CoV-2). This novel variant has crossed the barriers of Asia for the first time and has emerged as a true trans-continental virus pitching a serious epidemiological challenge to the national and international public health authorities. However, focusing on today's reality, it may happen that we have to live with this zoonotic pathogen in the years to come till the herd immunity develops in the population and/or immunization through effective candidate vaccine. Continuous viral surveillance in human and reservoir hosts is needed for early preparedness to combat and contain the future outbreak if any. A comprehensive scientific policy and management strategy are needed for wild life conservation and wild animal consumption from eco-epidemiological perspectives. This would reduce the man-animal encounter and lessen the possibility of spillover of zoonotic pathogen, especially with diverse host range, to human community.

\section{Conflict of Interest: None}




\section{References}

1. Johnson C, Hitchens P, Evans T et al. Spillover and pandemic properties of zoonotic viruses with high host plasticity. Sci rep 2015; 5: e14830.

2. Lu H, Stratton CW, Tang YW. Outbreak of pneumonia of unknown etiology in Wuhan, China: The mystery and the miracle. J Med Virol 2020; 92(4): 401-402.

3. World Health Organization. 2020. WHO DirectorGeneral's Remarks at the Media Briefing on 2019nCoV. 2020.

4. Fan Y, Zhao K, Shi ZL et al. Bat Coronaviruses in China. Viruses 2019; 11(3): 210.

5. Vijaykrishna D, Smith GJD, Zhang JX et al. Evolutionary insights into the ecology of coronaviruses. J Virol 2007; 81(15): 8371.

6. Lu R, Zhao X, Li J et al. Genomic characterization and epidemiology of 2019 novel coronavirus: implications for virus origins and receptor binding. Lancet 2020; 395(10224): 565-574.

7. Cutler SJ, Fooks AR, van der Poel WH. Public health threat of new, reemerging, and neglected zoonoses in the industrialized world. Emerg Infect Dis 2010; 16(1): 1-7.

8. World Health Organization, 2020. www.who. int (Accessed on $25^{\text {th }}$ April, 2020). Available from: https://www.who.int/emergencies/diseases/novelcoronavirus-2019/situation-reports.

9. Kahn JS, McIntosh K. History and recent advances in coronavirus discovery. Pediatr Infect Dis J 2005; 24(11 Suppl): S223-6.

10. Drosten C, Günther S, Preiser W et al. Identification of a novel coronavirus in patients with severe acute respiratory syndrome. N Engl J Med 2003; 348(20): 1967-1976.

11. Ksiazek TG, Erdman D, Goldsmith CS et al. A novel coronavirus associated with severe acute respiratory syndrome. N Engl J Med 2003; 348(20): 1953-1966.

12. Peiris JS, Lai ST, Poon LL et al. Coronavirus as a possible cause of severe acute respiratory syndrome. Lancet 2003; 361(9366): 1319-1325.

13. Song HD, Tu CC, Zhang GW et al. Cross-host evolution of severe acute respiratory syndrome coronavirus in palm civet and human. Proc Natl Acad Sci U S A 2005; 102(7): 2430-2435.

14. Lau SK, Woo PC, Li KS et al. Severe acute respiratory syndrome coronavirus-like virus in Chinese horseshoe bats. Proc Natl Acad Sci U S A 2005; 102(39): 1404014045.

15. Li W, Shi Z, Yu M et al. Bats are natural reservoirs of SARS-like coronaviruses. Science 2005; 310(5748): 676-679.

16. Zaki AM, van Boheemen S, Bestebroer TM et al. Isolation of a novel coronavirus from a man with pneumonia in
Saudi Arabia. N Eng/ J Med 2012; 367(19): 1814-1820.

17. Guo YR, Cao QD, Hong ZS et al. The origin, transmission and clinical therapies on coronavirus disease 2019 (COVID-19) outbreak - an update on the status. Mil Med Res 2020; 7(1): 11.

18. Guan $Y$, Zheng BJ, He YQ et al. Isolation and characterization of viruses related to the SARS coronavirus from animals in southern China. Science 2003; 302(5643): 276-278.

19. Reusken CB, Raj VS, Koopmans MP et al. Cross host transmission in the emergence of MERS coronavirus. Curr Opin Virol 2016; 16: 55-62.

20. Chatterjee R, Bhattacharya S. Could novel corona virus (SARS-CoV-2) be the evolving face of a new generation of genetically complex epidemiological challenges? Malaysian J. Med Res 2020; 4(2): 49-52.

21. Ji W, Wang W, Zhao X et al. Cross-species transmission of the newly identified coronavirus 2019-nCoV. J Med Virol 2020; 92(4): 433-440.

22. Cheng ZJ, Shan J. 2019 Novel coronavirus: where we are and what we know. Infection 2020; 48(2): 155-163.

23. Zheng J. SARS-CoV-2: an emerging coronavirus that causes a global threat. Int J Biol Sci 2020; 16(10): 16781685.

24. Shi J, Wen Z, Zhong G et al. Susceptibility of ferrets, cats, dogs, and other domesticated animals to SARScoronavirus 2 [Published online ahead of print, 2020 Apr 8]. Science 2020; eabb7015.

25. Salata C, Calistri A, Parolin C et al. Coronaviruses: a paradigm of new emerging zoonotic diseases. Pathog Dis 2019; 77(9): ftaa006.

26. Wang LF, Shi Z, Zhang $S$ et al. Review of bats and SARS. Emerg Infect Dis 2006; 12(12):1834-1840.

27. Banerjee A, Kulcsar K, Misra V et al. Bats and coronaviruses. Viruses 2019; 11(1): 41.

28. Griffin DR. Migrations and homing in bats In Wimsatt WA (ed.) Biology of bats, Academic Press, New York, USA. 1970; 233-264.

29. Calisher $\mathrm{CH}$, Childs JE, Field HE et al. Bats: important reservoir hosts of emerging viruses. Clin Microbiol Rev 2006; 19(3): 531-545.

30. Yadav PD, Aich AS, Nyayanit DA et al. Detection of coronaviruses in Pteropus \& Rousettus species of bats from different States of India. Indian J Med Res 2020.

31. Angelsen A, Kaimowitz D. Rethinking the causes of deforestation: lessons from economic models. World Bank Res Obs 1999; 14(1): 73-98.

32. Sehgal RN. Deforestation and avian infectious diseases. J Exp Biol 2010; 213(6): 955-960.

33. Leroy EM, Kumulungui $B$, Pourrut $X$ et al. Fruit bats as reservoirs of Ebola virus. Nature 2005; 438(7068): 575-576.

34. Afelt A, Lacroix A, Zawadzka-Pawlewska U et al. 
Distribution of bat-borne viruses and environment patterns. Infect Genet Evol 2018; 58: 181-191.

35. Walsh MG, Wiethoelter A, Haseeb MA. The impact of human population pressure on flying fox niches and the potential consequences for Hendra virus spillover. Sci Rep 2017; 7: 8226.

36. Brown C. Emerging zoonoses and pathogens of public health significance--an overview. Rev Sci Tech 2004; 23(2): 435-442.

37. Mavroidi N. Transmission of zoonoses through immigration and tourism. Vet Ital 2008; 44(4): 651-656.

38. Dobson AP, Kutz S, Pascual M et al. Pathogens and parasites in a changing climate. Adv Appl Biodivers Sci 2003; 4: 33-38.

39. Harvell CD, Mitchell CE, Ward JR, et al. Climate warming and disease risks for terrestrial and marine biota. Science 2002; 296(5576): 2158-62.

40. Patz JA, Graczyk TK, Geller N et al. Effects of environmental change on emerging parasitic diseases. Int J Parasitol 2000; 30(12-13): 1395-405.

41. Halford WP, Gebhardt BM, Carr DJ. Mechanisms of herpes simplex virus type 1 reactivation. J Virol 1996; 70: 5051-5060.

42. Mehta SK, Cohrs RJ, Forghani B et al. Stress-induced subclinical reactivation of varicella zoster virus in astronauts. J Med Virol 2004; 72(1): 174-179.

43. Morse SS. Factors in the emergence of infectious diseases. Emerg Infect Dis 1995; 1(1): 7-15.

44. Wang LF, Cowled C. Bats and viruses: a new frontier of emerging infectious diseases. John Wiley Sons Inc, Hoboken, NJ, USA. 2015.

45. Monchatre-Leroy E, Boué F, Boucher JM et al. Identification of alpha and beta coronavirus in wildlife species in france: bats, rodents, rabbits, and hedgehogs. Viruses 2017; 9(12): 364.

46. Chen W, Yan M, Yang L et al. SARS-associated coronavirus transmitted from human to pig. Emerg Infect Dis 2005;11(3): 446-448.

47. Bhattacharya S. Development and disease: Interpretation of inter relationship in the context of mosquito-borne maladies. Sci Cult 2012; 78 (1-2): 47-53.

48. Hueffer K, Murphy M. Rabies in Alaska, from the past to an uncertain future. Int J Circumpolar Health 2018; 77(1): 1475185.

49. Ostfeld R, Keesing F. Biodiversity and disease risk: the case of Lyme disease. Conserv Biol 2000; 14: 722-728.

50. LoGiudice K, Ostfeld RS, Schmidt KA et al. The ecology of infectious disease: effects of host diversity and community composition on Lyme disease risk. Proc Natl Acad Sci U S A 2003; 100(2): 567-571.

51. Wood CL, Lafferty KD. Biodiversity and disease: a synthesis of ecological perspectives on Lyme disease transmission. Trends Ecol Evol 2013; 28(4): 239-247.

52. Keesing F, Holt RD, Ostfeld RS. Effects of species diversity on disease risk. Ecol Lett 2006; 9(4): 485-498.

53. Luis AD, Kuenzi AJ, Mills JN. Species diversity concurrently dilutes and amplifies transmission in a zoonotic host-pathogen system through competing mechanisms. Proc Natl Acad Sci U S A 2018; 115(31): 7979-7984. 